\title{
Development of Ring-End Crush Testing JIG of Glass Fiber Structure Sheet and Estimation of In-Plane Compressive Strength of that Sheet
}

\author{
Songtam Laosuwan ${ }^{1 *}$, Shigeru Nagasawa ${ }^{2}$, \\ ${ }^{1}$ Graduate student, Nagaoka University of Technology, 1603-1 Kamitomioka, Nagaoka 940-2188, Japan. \\ ${ }^{2}$ Department of Mechanical Engineering, ditto. \\ *1songtam@stn.nagaokaut.ac.jp, 로aga@mecha.nagaokaut.ac.jp
}

\section{Introduction.}

Due to its good strength and lightweight, glass fiberbased structural sheet (GFSS) is expected to use for a sort of shield wall and packaging structure. To develop a packaging wall/panel filled and painted with appropriate mediums, some fundamental mechanical properties must be revealed. The in-plain buckling strength of panel of GFSS is not yet understood well. In this study, in order to estimate the ring-end-crush strength of raw GFSS materials, a special prototype measurement JIG has been developed, and the compressive test has been carried out, by varying the mechanical condition for stably supporting the both ends of cylindrical panel of GFSS.

\section{Experimental method.}

The raw GFSS material was produced using twisted yarn, E-glass of Nittobo, ECG75-1/2-3.8S. Fig.1 shows a side view of GFSS [1].

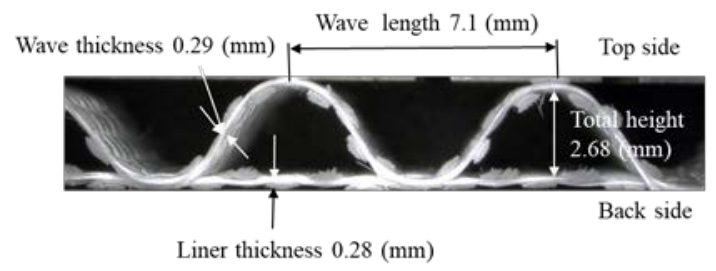

Fig. 1 Side view of two flutes of GFSS.

Figure 2 shows a layout of ring crush JIG and the winding condition of GFSS specimen. Groove depth of $10 \mathrm{~mm}$ and its width of $3.5 \mathrm{~mm}$ were designed as representative. There were two patterns as (a) the waveinside and (b) the wave-outside pattern.

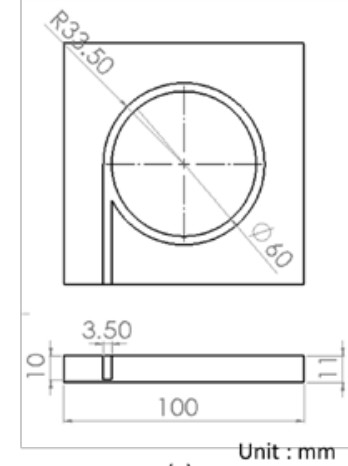

(a)

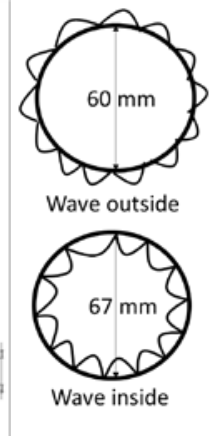

(b) $\begin{array}{ll}\text { (a) A holder JIG } & \text { (b) Winding patterns of GFSS }\end{array}$

Fig. 2 Schematics of testing holder and winding pattern.

Panel length of the wave inside and that of the wave outside were $207 \mathrm{~mm}$ and $193 \mathrm{~mm}$, respectively. Height of the panel was $30 \mathrm{~mm}$. Here, overlapped length of 7 mm was chosen for each mode.

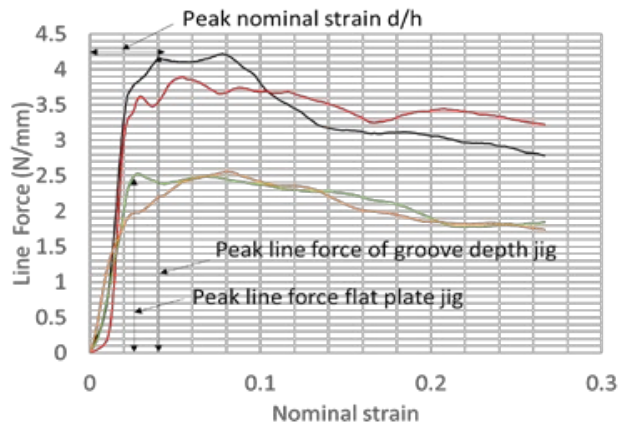

Figure 3 Representative compressive load response.

In Fig. 3, the peak maximum of line force and its position of compressed stroke were measured, when exchanging the upper flat plate and the upper grooved plate holder against the lower grooved holder. Namely, a cylindrical panel of GFSS was mounted on the upper/lower holding JIG and compressed by a press machine with a velocity of $12.5 \mathrm{~mm} / \mathrm{s}$ until reaching a specified stroke.

Results and discussion.

Table 1. Buckling strength with flat plate and grooved holder. Average (standard deviation)

\begin{tabular}{|l|l|l|}
\hline Case & Flat plate $\mathrm{N} / \mathrm{mm}$ & Grooved holder $\mathrm{N} / \mathrm{mm}$ \\
\hline Wave inside & $2.85(0.35)$ & $\begin{array}{c}3.92(0.18) \text { and } \\
2.25(0.06)\end{array}$ \\
\hline Wave outside & $2.53(0.19)$ & $3.09(0.04)$ \\
\hline
\end{tabular}

Table 1 shows results of the 1 st buckling strength as a line force of compressed GFSS panel, in cases of the wave inside and the wave outside, comparing with flat the plate holder and the grooved holder.

(1) In case of the grooved, the buckling strength of wave inside model had the higher than that of the wave outside model, because of difference of wave pitch and its height after compressed or tensiled in the winding pattern.

(2) When adding an instant adhesive liquid onto the edge surface of GFSS panel, the buckling strength remarkably increased. Its solidification of the edge of panel seems to reinforce the buckling resistance.

(3) In case of $3.5 \mathrm{~mm}$ groove, two levels of buckling strength occurred. When comparing the width of groove $3.5 \mathrm{~mm}$ with the case of $4 \mathrm{~mm}$, the latter (4 $\mathrm{mm}$ ) had the lower strength of $2 \mathrm{~N} / \mathrm{mm}$. It causes a large bending at a middle zone of panel, and makes the buckling strength weak.

(4) When fixing the overlapped zone of panel by using a stapler, the buckling behavior was almost not changed for a shallow indentation.

\section{References.}

(1) Kubo corporation, GFSS, <http://www.kuboco.net/> (accessed on March 1st, 2017). 